\title{
Parameter Analysis and Optimization of Electrolytic In-Process Dressing Grinding on Ceramics
}

Chang-Pin Lin

Associate Professor, Department of Mechanical and Marine Engineering, National Taiwan Ocean University, Keelung, Taiwan 202, R.O.C., cplin@newton.me.ntou.edu.tw

Kuei-Miao Hsiao

Graduate Student, Department of Mechanical Engineering, National Chung Hsing University, Taichung, Taiwan 250, R.O.C.

Chun-Chung Wu

Senior Engineer, Department of Environmental Protection, Taipei Municipal Government, Taipei, Taiwan 110, R.O.C.

Follow this and additional works at: https://jmstt.ntou.edu.tw/journal

Part of the Engineering Commons

\section{Recommended Citation}

Lin, Chang-Pin; Hsiao, Kuei-Miao; and Wu, Chun-Chung (2003) "Parameter Analysis and Optimization of Electrolytic InProcess Dressing Grinding on Ceramics," Journal of Marine Science and Technology. Vol. 11: Iss. 2, Article 5. DOI: $10.51400 / 2709-6998.2286$

Available at: https://jmstt.ntou.edu.tw/journal/vol11/iss2/5

This Research Article is brought to you for free and open access by Journal of Marine Science and Technology. It has been accepted for inclusion in Journal of Marine Science and Technology by an authorized editor of Journal of Marine Science and Technology. 


\title{
PARAMETER ANALYSIS AND OPTIMIZATION OF ELECTROLYTIC IN-PROCESS DRESSING GRINDING ON CERAMICS
}

\author{
Chang-Pin Lin*, Kuei-Miao Hsiao**, and Chun-Chung $\mathrm{Wu}^{* * *}$
}

Key words: electrolytic in-process dressing, parameter optimization, ceramics, neuro-fuzzy.

\begin{abstract}
Ceramic materials have been studied and used in considerable industrial applications due to their high hardness and strength at high temperature and extreme wear resistance. However, the machining costs of these materials may reach as high as $90 \%$ of their total component costs and the grinding of these materials are much more susceptible to surface damage as compared to metals. Electrolytic InProcess Dressing (ELID) grinding can be used to machine hard and brittle materials, such as aluminum oxide $\left(\mathrm{Al}_{2} \mathrm{O}_{3}\right)$, that are difficult to be machined by conventional grinding processes to achieve high surface quality and high material removal rate. The effect of each major machining parameter in processing $\mathrm{Al}_{2} \mathrm{O}_{3}$ on the surface roughness and material removal rate were analyzed and presented. Furthermore, by using the process models built with Neuro-fuzzy theory, an optimization algorithm is constructed for multiple objectives and which incorporates tournament sharing selection and G-bit local search is applied to find the machining parameters for achieving the best product quality and/or production rate.
\end{abstract}

\section{INTRODUCTION}

The grinding process of shaping materials by utilizing hard abrasive particles as cutting medium has been a major manufacturing process to produce precision mechanical parts and is currently being used extensively for processing optical and electronic parts. It is usually used as a final machining process to produce smooth surfaces and fine tolerances on various types of materials, especially on hard and brittle materials, such as ceramics. Structural ceramics has found wide applications that require high temperature and high stress endurance capabilities, and aluminum oxide $\left(\mathrm{Al}_{2} \mathrm{O}_{3}\right)$

Paper Submitted 04/08/03, Accepted 06/13/03. Author for Correspondence: Chang-Pin Lin, E-mail: cplin@newton.me.ntou.edu.tw.

*Associate Professor, Department of Mechanical and Marine Engineering, National Taiwan Ocean University, Keelung, Taiwan 202, R.O.C.

**Graduate Student, Department of Mechanical Engineering, National Chung Hsing University, Taichung, Taiwan 250, R.O.C.

***Senior Engineer, Department of Environmental Protection, Taipei Municipal Government, Taipei, Taiwan 110, R.O.C. studied in this research is one of those. Modern grinding process has focused on achieving accurate geometry and precise surface finish on hard and brittle materials used in high-tech industries such as silicon wafers, glasses, and ceramics [14]. In addition, heavy-duty grinding operations have been developed to cut and remove materials more efficiently with limited surface finish requirements. Precision slicing of silicon wafers, for producing integrated circuit chips, use thin abrasive disks or saws only $20 \mu \mathrm{m}$ thick to produce silicon slices. However, in ceramic grinding, low grinding efficiency, frequent surface damages and critical strength degradation result in high machining cost. Creep-feed grinding of ceramic parts used in electronic and optical products use conventional grinding tools with higher cutting depth and lower feed rate to achieve high material removal rate [1]. One major task for a successful grinding process is the preparation of the grinding wheel that includes truing and dressing. Truing is to shape the grinding wheel surface so that the spinning wheel runs true with minimum run-out from its macroscopic shape. Dressing is the process to condition the grinding wheel surface to achieve appropriate abrasive particle protrusion so as to achieve designated grinding behavior. In recent years, a new in-process dressing technique called Electrolytic In-Process Dressing (ELID) used on grinding wheels with metal bonded super abrasives (diamond or $\mathrm{CBN}$ ) was developed to facilitate the production rate of grinding processes with increasing surface quality for processing hard and brittle materials [19]. Followup experimental studies on ELID have been conducted extensively in $[8,10,20]$ and some for ceramic parts. [2] More work has been carried out to determine the effect of ELID grinding in ductile mode on brittle materials that decreases the surface fracture and fragmentation and enables higher material removal rate [3]. Other efforts on studying the mechanism of grinding process for ceramics have been conducted to find the grit depth of cut and the active cutting points per unit area in order to control the cutting forces [12], and to evaluate the strength degradation which could limit higher process performance [15]. Process optimization has also been 
studied extensively for various manufacturing processes including grinding $[11,18]$ The current work on studying the mechanism of ELID was carried out to analyze the effects of current duty ratio on cutting forces, surface roughness and tool wear [13]. The increasing importance of manufacturing system automation and integration has prompted an integrated precision grinding system to be developed that can obtain optimal product quality and cost by selecting appropriate process parameters and that can be implemented in lowcost conventional grinding machine centers. Therefore, the research work presented in this paper has concentrated on two objectives: 1. Compare the product surface quality produced by non-ELID and ELID grinding process, and analyze the effects of process parameters on surface roughness and material removal rate from the experimental data gathered by a conventional grinding machine center to process ceramic parts. 2. Process parametric optimization for multiple objectives including surface roughness and material removal rate. In order to achieve these two objectives, the Artificial Neural Network, Fuzzy Theory and Genetic Algorithm for machine learning and optimization were studied extensively and applied selectively [6, 7, 9, 16, 17]. In addition, the ELID precision grinding machine center is integrated with modern CAD/CAPP/CAM software and controlling hardware. Finally, the whole system was tested under regular operating conditions and the results were used to adjust both system parameters of the machine center and the processing parameters to achieve optimal surface quality and material removal.

\section{ELID GRINDING MECHANISM AND EXPERIMENTAL SYSTEM}

The principle of Electrolytic In-Process Dressing (ELID) is based on the same theory used in the ElectroChemical Machining (ECM) process that removes metals from the anode (workpiece) by injecting electrolyte between the anode and cathode (tool) and connecting a DC current between them. A common application of ECM is electrolytic grinding that applies ECM between the grinding wheel and work piece during abrasive process. ECM speeds up the metal removal rate of the grinding process and increases the life of the grinding wheel. However, the use of harmful electrolytes in ECM and the need for a continuous dressing mechanism to process hard and brittle materials have promoted for studies on in-process dressing systems of grinding wheel. In 1988, Dr. Ohmori at the Institute of Physical and Chemical Research, Tokyo, Japan, proposed the idea of the ELID grinding process in order to increase both the surface quality and the production rate of grinding hard and brittle materials. It applies current between the metal bonded grinding wheel that was connected to the positive terminal of a power supply and a fixed electrode to the negative. Electrolysis occurs through the supply of a conductive grinding fluid between the electrode and grinding wheel [19].

\section{ELID grinding mechanism}

The steps of the ELID is shown in Figure 1 and detailed as follows.

(1) Start of Pre-dressing: Cast iron bond material is ionized into $\mathrm{Fe}^{+2}$ that is then removed by electrolyte and the super abrasive grains protrude.

(2) End of Pre-dressing: Hydration and/or oxidation of the cast iron-bonded material will form an insulation layer on the surface of the grinding wheel and reduce the electrolytic effect until stabilization.

(3) Start of ELID Grinding Process: The grains are worn and the insulation layer is thinning while the grinding process continues.

(4) Stabilization of ELID Grinding Process: Electrolysis restarts due to the thinning of the insulation layer and insulation layer will start to be reformed until establishment, ie., stabilization recovers.

Research, studying the process efficiency of ELID grinding on ceramics, has been conducted by Ohmori et al. [2, 20] with the intents of reducing the processing cost by maximizing the material removal rate due to the high percentage (up to $90 \%$ ) of the component costs in grinding with about $15 \%$ for metal parts. Other studies, investigating the surface quality of ELID Lapping pro-

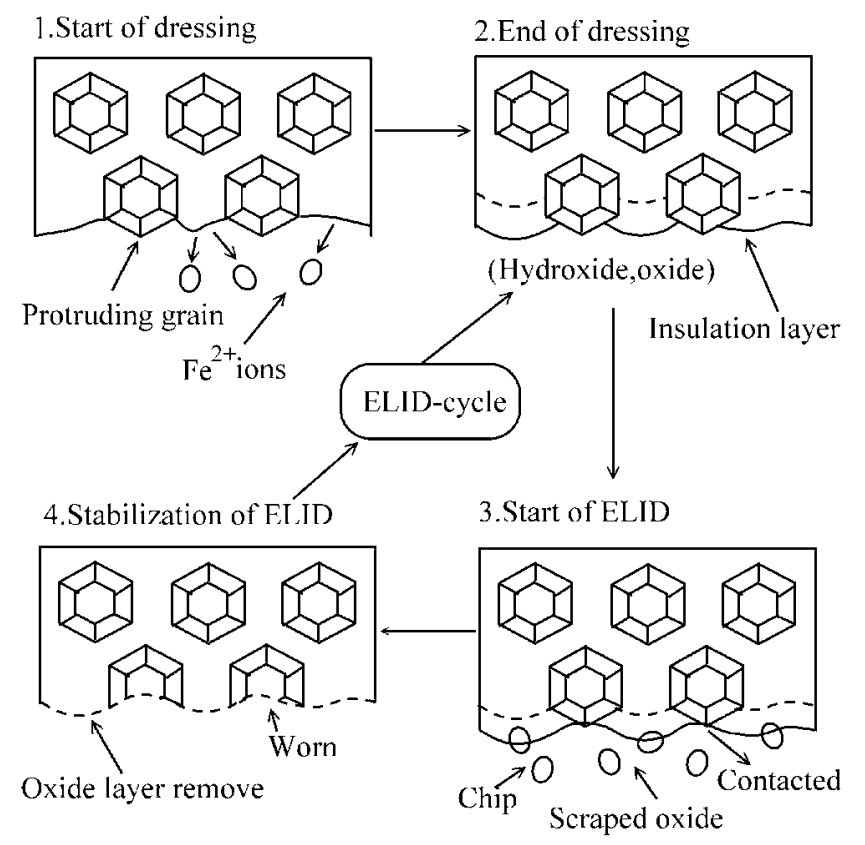

Fig. 1. Steps in electrolytic in-process dressing. 
cesses for ceramics were reported in [8], they used grinding wheels with mesh sizes as low as \#8000 to produce parts with less than $60 \mathrm{~nm}$ in $R_{y}$.

\section{ELID grinding experimental system}

The ELID grinding system used for experiments conducted in this research work includes an ELID electrolysis module as shown in Figure 2. This module consists of an electrode, a gap adjustment mechanism, and a set of electrolyte injecting nozzles. The complete system is detailed below.

1. Machine center: A conventional grinding machine center is used by adding a CNC control module and a power supply system and is shown in Figure 3.

2. Power supply: An EDM (electro-discharge machining) power supply was modified to achieve the following: current $=1 \mathrm{~A} \sim 30 \mathrm{~A}$, voltage $=10 \mathrm{~V} \sim 60 \mathrm{~V}$, and on/ off time $=1 \mu \mathrm{s} \sim 12 \mu \mathrm{s}$. The gap between the electrode and grinding wheel could be adjusted in the range $0.2 \sim 0.3 \mathrm{~mm}$ to ensure right electrolytic effect on the metal bond.

3. Grinding wheel: A cast iron bonded straight wheel, $\phi 300 \mathrm{~mm} \times 10 \mathrm{~mm}$, with diamond super abrasive of \#2000 (average grain diameter $8 \mu \mathrm{m}$ ).

4. Grinding fluid/Electrolyte: Noritake Cool.CEM chemical fluid diluted to 1:50.

It should be noted that the characteristics of ELID for the equipment used above shows that: no special machine is required, a low-cost conventional EDM or ECM power supply can be used, and no harmful electrolyte is needed.

Three sets of experiments are conducted: in the first set of training experiments data is used to analyze the effects of machining process parameters on surface roughness and cutting forces and to build the process model for optimization process; in the second set, testing experimental data is used to calculate the errors of the model prediction; and the third set, with the optimal

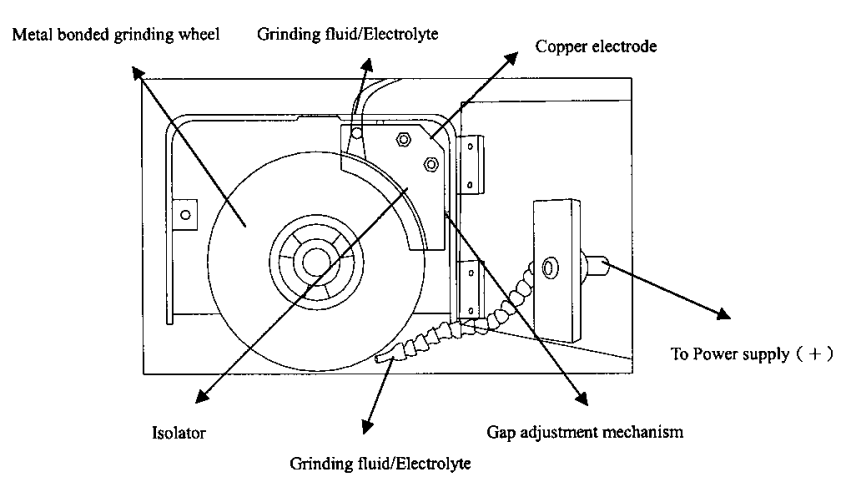

Fig. 2. ELID electrolysis module. process parameters resulting from the Hybrid MOGA algorithm is used to check the applicability of the optimization algorithm.

\section{GRINDING SURFACE GEOMETRY}

The surface roughness that represents the microgeometry or topography of machining surfaces has been used as an important index for product quality. It is much more difficult to model and predict the surface roughness of a grinding process than other processes including turning and milling that use cutting tools with well defined geometry. The grinding wheel has randomly distributed cutting points bonded to its surface, these cause non-uniform topology including the protrusions of the cutting points and the lengths of spacing between successively active cutting points. In the theories of fracture mechanics, the surface quality of a machined surface plays a major role in estimating the endurance limit and predicting fatigue failures.

Based on the grinding geometry and kinematics, the ideal surface roughness can be estimated by modeling the cutting processes of the abrasive cutting points [14]. It is much more difficult to model the grinding machining processes than turning and milling due to the randomness of the location and numbers of the cutting points on the wheel surface. Therefore, assumptions that include equally spaced and protruded cutting points are made to simplify the cutting process. By analyzing a straight surface grinding process as shown in Figure 4, the following results are calculated.

$$
S_{c}=\frac{v_{w} L}{v_{s}}
$$

where $v_{w}$ is the workpiece velocity, $v_{s}$ the wheel velocity, and $L$ the average successive cutting point spacing. The arithmetic average surface roughness $R_{a}$ can then be estimated by equation (2) as follows.

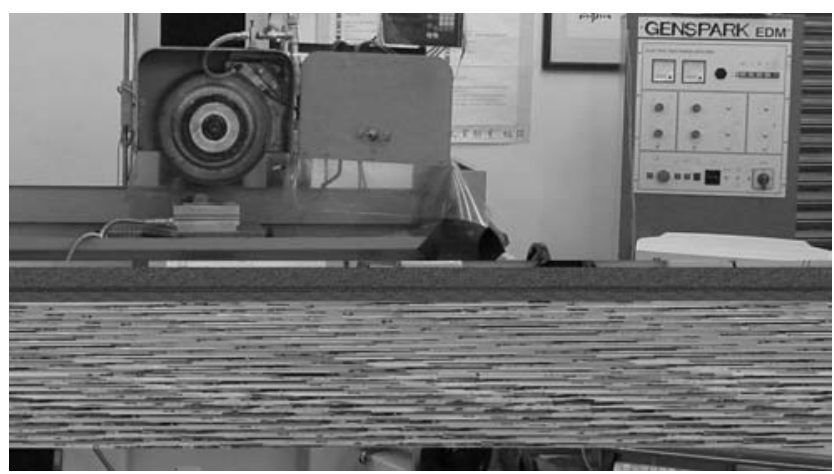

Fig. 3. ELID grinding machine center. 


$$
R_{a} \approx \frac{1}{9 \sqrt{3}} \frac{S_{c}^{2}}{d_{s}}
$$

where $d_{s}$ is the wheel diameter which is used to approximate the trochoidal path.

In reality, the cutting points on the grinding wheel are not equally spaced apart and do not protrude uniformly, therefore, Li and Liao [12] have done some work to estimate the active successive cutting points and a more realistic $L$ and also to calculate the undeformed chip thickness $h_{m}$ that can be correlated to the surface roughness. The undeformed chip thickness for a given topography depends on both the velocity ratio $v_{w} / v_{s}$ and the depth of cut $a$ [14]. The surface roughness is found to increase with the velocity ratio but decrease with the depth of cut by less sensibility as shown in equation (3).

$$
R_{a} \propto\left(\frac{v_{w}}{v_{s}}\right) a^{1 / 2}
$$

\section{EXPERIMENTAL RESULTS AND ANALYSIS}

ELID grinding operations on $\mathrm{Al}_{2} \mathrm{O}_{3}$ ceramic parts $\left(50 \times 25 \times 12.5 \mathrm{~mm}\right.$ and density $\left.3.92 \mathrm{~g} / \mathrm{cm}^{3}\right)$ by the equipment described in previous section were performed with \#2000 (grit size $8 \mu \mathrm{m}$ ) diamond super abrasive cast iron bonded grinding wheel. The equipment was calibrated and the grinding wheel was balanced and trued before the ELID grinding operations proceeded. With the experience gained from previous research work, surface damages and strength degradation can be avoided by minimizing the undeformed chip thickness $h_{m}$. Due to the greater sensitivity of feed rate than depth of cut to $h_{m}$ as shown in equation (4), larger depth of cut and lower feed rate were chosen for experiments.

$$
h_{m} \propto\left(\frac{v_{w}}{v_{s}}\right)^{1 / 2} a^{1 / 4}
$$

Experiments were planned with four machining parameters: Cutting speed $=28.3 \sim 47.1 \mathrm{~m} / \mathrm{s}$, depth of cut $=10 \sim 30 \mu \mathrm{m}$, feed rate $=6 \sim 30 \mathrm{~mm} / \mathrm{min}$, and current $=10 \sim 30 \mathrm{~A}$. Other conditions include voltage $=60 \mathrm{~V}$ and current on/off time $=0.2 \mu \mathrm{sec}$. Based on these conditions, a set of ELID grinding experiments was

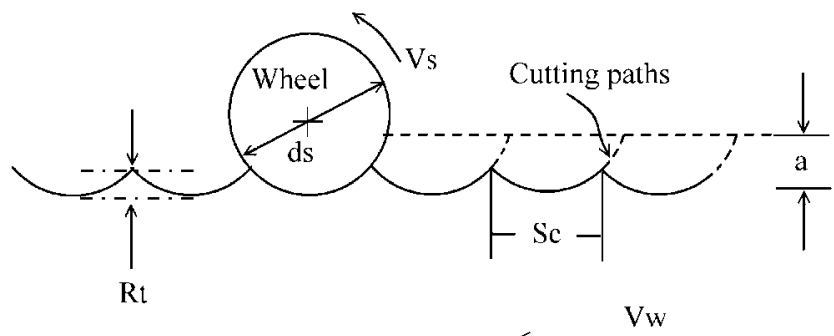

Fig. 4. Idea surface profile generated by a uniform wheel topology. performed that includes a training data set for parameter analysis and model building and a testing data set for prediction. The experimental results include surface roughness $(R a)$, actual material removal rate (MRR), and cutting forces. Measurements of surface roughness were performed on a Hommel T2000 measuring instrument and measurements of cutting forces were performed by a Kistler 9256A1 3-axis dynamometer.

\section{Effects of ELID}

Experiments of grinding performed with and without applying ELID were compared. Due to increasing grit protrusions on surface of the grinding wheel by ELID, contact areas between the cutting points and work piece can be reduced and cutting forces can be reduced that will then improve the surface quality of work pieces. Figure 5 shows the changes of surface roughness for various depths of cut and feed rates. The average improvement of surface roughness $R a$ by applying ELID on grinding is about $13 \%$ with the highest improvement of $19 \%$. Figure 6 shows the reduction of tangential cutting force $F_{t}$ for various depths of cut and feed rates. The average reduction of tangential cutting force $F_{t}$ is about $50 \%$ with the highest reduction of $77 \%$. Figure 7 shows the reduction of normal cutting force $F_{n}$ for various depths of cut and feed rates. The average reduction of normal cutting force $F_{n}$ is about $21 \%$ with the highest reduction of $41 \%$.

From the ELID grinding experimental data shown in Figure 5, the improvement in surface roughness by decreasing the depth of cut is greater than that by decreasing feed rate. In addition, the more the feed rate increases the less degree of improvement on surface

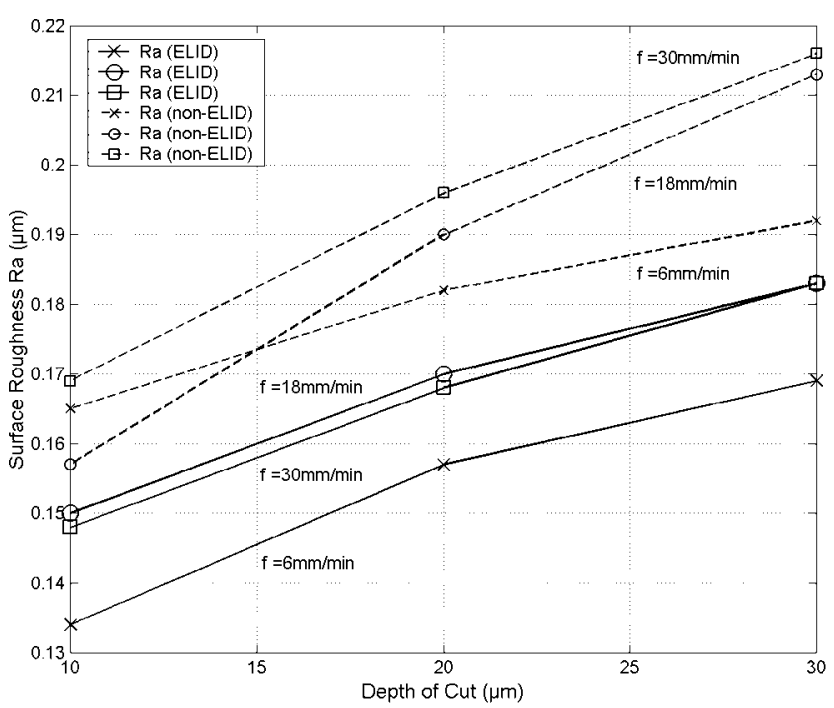

Fig. 5. Effects of depth of cut and feed rate on surface roughness. 
roughness can be achieved.

\section{Statistic analysis}

The next part of analysis includes building second order mathematical models by regression techniques for surface roughness and cutting forces, performing F-test that is based on analysis of variance (ANOVA) to verify

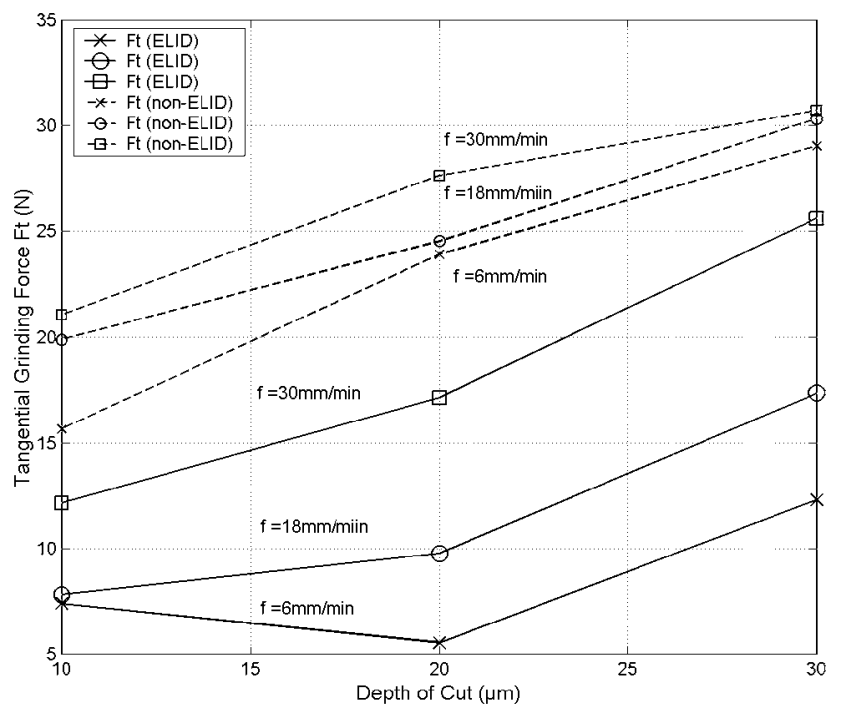

Fig. 6. Effects of depth of cut and feed rate on tangential grinding force. the applicability of those models, and finally finding the levels of contribution to surface roughness and cutting forces by each process parameter with $t$-test. According to a typical experimental design technique, 27 ELID grinding experiments were performed in this analysis. The SAS statistic software was used to perform the analysis and the regression models are built with estimated parameters' coefficients listed in Table 1 for

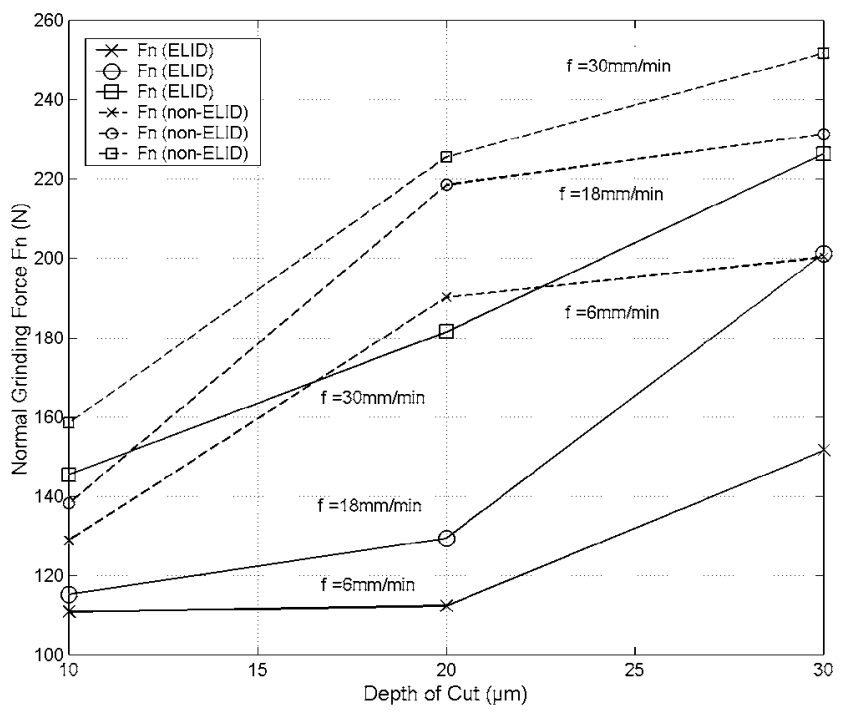

Fig. 7. Effects of depth of cut and feed rate on normal grinding force.

Table 1. Statistic analysis of the ELID grinding process

\begin{tabular}{ccccccc}
\hline & \multicolumn{2}{c}{$\begin{array}{c}\boldsymbol{R}_{\boldsymbol{a}} \\
\text { F-ratio }\end{array}$} & \multicolumn{2}{c}{$\begin{array}{c}\boldsymbol{F}_{\boldsymbol{t}} \\
\text { F-ratio }\end{array}$} & \multicolumn{2}{c}{$\begin{array}{c}\boldsymbol{F}_{\boldsymbol{n}} \\
\text { F-ratio } \\
\text { 3.8.533 }\end{array}$} \\
\hline Parameter & $\begin{array}{c}\text { Parameter } \\
\text { Estimate }\end{array}$ & $\boldsymbol{T}$ for $\boldsymbol{H}_{\mathbf{0}}$ & $\begin{array}{c}\text { Parameter } \\
\text { Estimate }\end{array}$ & $\boldsymbol{T}$ for $\boldsymbol{H}_{\mathbf{0}}$ & Parameter & $\boldsymbol{T}$ for $\boldsymbol{H}_{\mathbf{0}}$ \\
& & & & & \\
\hline Intercept & 0.062184 & 1.067 & 87.666098 & 2.090 & 273.510907 & 0.939 \\
$v$ & 0.001350 & 0.492 & -4.074236 & -2.063 & -15.736141 & -1.148 \\
$a$ & 0.003931 & 2.403 & 0.108313 & 0.0919 & 0.670072 & 0.0819 \\
$f$ & 0.001582 & 1.310 & 0.744425 & 0.856 & 9.572244 & 1.585 \\
$I$ & 0.000612 & 0.374 & -0.852764 & -0.724 & -3.868325 & -0.473 \\
$v_{2}$ & 0.000006287 & 0.180 & 0.050594 & 2.017 & 0.239865 & 1.377 \\
$v_{a}$ & -0.000043262 & -1.809 & -0.003898 & -0.226 & 0.026242 & 0.219 \\
$a_{2}$ & -0.000034444 & -1.119 & 0.000425 & 0.0192 & 0.029363 & 0.191 \\
$v_{f}$ & -0.000006107 & -0.306 & -0.015801 & -1.101 & -0.083365 & -0.837 \\
$a_{f}$ & -0.000000370 & -0.0198 & 0.010133 & 0.752 & 0.043983 & 0.470 \\
$f_{2}$ & -0.000018133 & -0.848 & 0.010733 & 0.697 & -0.104036 & -0.973 \\
$v_{I}$ & -0.000019385 & -0.811 & 0.008821 & 0.512 & 0.047827 & 0.400 \\
$a_{I}$ & 0.000004222 & 0.188 & 0.015542 & 0.960 & 0.071685 & 0.638 \\
$f_{I}$ & -0.000017222 & -0.919 & -0.019853 & -1.472 & -0.095711 & -1.022 \\
$I_{2}$ & 0.000002222 & 0.0722 & 0.012833 & 0.579 & 0.041935 & 0.272 \\
\hline
\end{tabular}

$* t_{0.05}(26)=2.056 ; t_{0.1}(26)=1.315$ 
surface roughness, tangential cutting force and normal cutting force respectively. The process parameters are: cutting speed $(v)$, depth of cut $(a)$, feed rate $(f)$, and current used for ELID $(I)$.

From the statistic analysis results as shown in table 1 , comparing to the standard value of $F$ ratio and $t$ values, $F_{0.05}(14,12)=2.643$ and $t_{0.05}(14,12)=2.056 /$ $t_{0.1}(14,12)=1.706$. The $F$ ratios in all three models are higher than 2.643 which means all three models are statistically applicable for this ELID grinding process. The dominant process parameters for surface roughness are depth of cut $a$ and cutting speed times depth of cut $v_{a}$, for tangential cutting force are constant $c$, cutting speed $v$ and square of cutting speed $v^{2}$, and for normal cutting force are feed rate $f$ and square of cutting speed $v^{2}$.

The SAS statistic software was again used to perform non-linear regression modeling to find the influence of some critical parameters for surface roughness, tangential cutting force and normal cutting force respectively and the results were shown in equations (5), (6) and (7).

$$
\begin{aligned}
& R \propto a^{0.112} f^{0.032} \\
& F_{t} \propto v^{-1.318} f^{0.38} \\
& F_{n} \propto v^{0.651} f^{0.173}
\end{aligned}
$$

\section{HYBRID MULTI-OBJECTIVE GENETIC ALGORITHM OPTIMIZATION}

In order to be able to predict accurately the quality of the machining parts and find the optimal process parameters, it is necessary to build a model of the complete ELID grinding process. Several non-analytical methods have been reviewed and a Neuro-Fuzzy algorithm was chosen to model the grinding process [17]. The ANFIS (Adaptive Neuro-Fuzzy Inference
Systems) algorithm [9] is based on both the Sugeno and Tsukamoto fuzzy model and is very efficient by running a hybrid learning algorithm. A common rule set with two fuzzy if-then rules is listed as follows,

Rule 1: If $x$ is $A_{1}$ and $y$ is $B_{1}$,

then $f_{1}=p_{1} x+q_{1} y+r_{1}$

Rule 2: If $x$ is $A_{2}$ and $y$ is $B_{2}$,

then $f_{2}=p_{2} x+q_{2} y+r_{2}$

Consequent parameters $p_{1}, q_{1}, r_{1}, p_{2}, q_{2}, r_{2}$ and the characteristic parameters used to define membership functions $A_{1}, A_{2}, B_{1}, B_{1}$ will be updated continuously through the hybrid learning process deduced from neural network theory by using existing input/output data. It is possible to build neuro-fuzzy network models from experimental data of the ELID grinding process with low error percentages that, however, causes higher prediction errors than regression modeling techniques. In order to reduce the prediction errors, more experimental data is required for neuro-fuzzy modeling but less number of experiments than complete combination of process parameters can be achieved by varying dominant parameters obtained from the statistic t-test analysis.

Models on surface roughness, material removal rate and cutting forces were built by using ANFIS neuro-fuzzy algorithm with data of 45 experiments that introduce extra experiments into the 27 used in regression analysis based on the $t$-test results. The prediction capabilities of these models were then verified by a set of 6 testing experiments and the average prediction error is about $5.9 \%$ as shown in Table 2.

Process optimization has attracted a lot of attentions as more process parameters emerged into the nontraditional manufacturing processes used to produce parts with surface roughness in micro or nano scale.

Table 2. Prediction errors of ANFIS model for the ELID grinding process

\begin{tabular}{ccccccccc}
\hline & & & & & Experimental & \multicolumn{2}{c}{ ANFIS Model } \\
\cline { 3 - 7 } No. & $\begin{array}{c}v \\
(\mathrm{~m} / \mathrm{min})\end{array}$ & $\begin{array}{c}a \\
(\mu \mathrm{m})\end{array}$ & $\begin{array}{c}f \\
(\mathrm{~mm} / \mathrm{min})\end{array}$ & $\begin{array}{c}I \\
(\mathrm{Amp})\end{array}$ & $\begin{array}{c}R a \\
(\mu \mathrm{m})\end{array}$ & $\begin{array}{c}R a \\
(\mu \mathrm{m})\end{array}$ & $\begin{array}{c}\text { error } \\
(\%)\end{array}$ \\
\hline 1 & 28.3 & 20 & 6 & 20 & 0.159 & 0.1451 & 8.74 \\
2 & 28.3 & 30 & 30 & 20 & 0.176 & 0.1689 & 4.03 \\
3 & 37.7 & 20 & 18 & 10 & 0.173 & 0.1769 & 2.25 \\
4 & 37.7 & 10 & 6 & 20 & 0.137 & 0.129 & 5.84 \\
5 & 47.1 & 30 & 6 & 20 & 0.171 & 0.1712 & 6.19 \\
6 & 47.1 & 10 & 30 & 20 & 0.161 & & average error & 5.9 \\
\hline
\end{tabular}


How to determine accurately and quickly the process parameter combination or combinations to produce products with best quality and production rate is the goal for most production engineer. Traditional multi-objective optimization algorithms transferred the problems into single-objective ones and provide only one weighted "best" solution. However, in the real world, there is no one optimal solution but a set of near optimal solutions for multiple objectives. In this paper we used Genetic Algorithm for solving process parametric optimization due to its capability to solve highly non-linear optimization problem non-analytically $[6,7,16]$. A set of nondominant solution, called Pareto set, of the process optimization problem will provide production engineers or decision makers more alternatives of choosing and running the production line. A Pareto set out of the candidate optimal solutions is defined as follows:

By solving an optimization problem with an objective function vector $u=\left\{u_{1}, \ldots, u_{n_{1}}, u_{n_{1}+1}, \ldots, u_{n_{1}+n_{2}}\right\}$ to minimize $u_{1}, \ldots, u_{n_{1}}$ and maximize $u_{n_{1+1}}, \ldots, u_{n_{1}+n_{2}}$, a Pareto optimal set $P$ can be separated from the set $U$ of all candidate optimal solutions and $\forall v \in P, u \in(U-P)$, $v_{i} \leq u_{i}\left(1 \leq i \leq n_{1}\right) \wedge v_{j} \geq u_{j}\left(n_{1}+1 \leq j \leq n_{2}\right)$.

Multi-Objective Genetic Algorithm (MOGA) has been proposed by Schaffer [21] in his Vector Evaluated Genetic Algorithm (VEGA) program. A set of subpopulations, one for each objective function, was generated during the selection step and the size of each subpopulation equals the total population divided by the number of objectives. The new population is then formed by combining the new sub-populations together and can be used to proceed to the next step of crossover and mutation. However, this algorithm is equivalent to linearly combining the fitness function to form one single fitness function that results to split subpopulations, each of them strong in one of the objectives. A rank-based fitness assignment method using the definition of Pareto Optimality was proposed by Goldberg [7] that divides the population into sub-populations with different ranks based on the non-dominant properties [4]. It ranks the non-dominated set in the current population rank 1 and removes the set from the population, and then repeat the process with next higher rank. Fonseca and Fleming [5] redefined the ranking scheme so that an individual's rank corresponds to the number of individuals in the current population by which it is dominated. The heavily dominated individuals are then given a worse chance to reproduce.

Conventional fitness sharing techniques have been shown to be effective in preventing genetic drift in multi-modal function optimization. According to that, the value of fitness function for an individual has to be divided by a number $s(d)$, called niche count, as shown in equation (8).

$$
f_{s}\left(x_{i}\right)=\frac{f\left(x_{i}\right)}{\sum_{j=1}^{n} s\left(d\left(x_{i}, x_{j}\right)\right)}
$$

where $s(d)=\left\{\begin{array}{cc}1-\frac{d}{\sigma_{\text {share }}} & \text { for } d \leq \sigma_{\text {share }} \\ 0 & \text { for } d>\sigma_{\text {share }}\end{array}\right.$,

$$
\sigma_{\text {share }} \text { : pre-selected radius for fitness sharing }
$$

A reproduction algorithm known as Tournament Selection that combines the Pareto optimality and niche count sharing is described below and shown in Figure 8: 1.Randomly pick $k$ individuals from the population to form a comparison set $C$ where $k$ was pre-chosen.

2.Pick 2 individuals from population to form set $T$

3. Based on the following to choose which one in set $T$ to be reproduced:

3.1 If $x_{1}$ in set $\mathrm{T}$ dominates every individual in set $C$ and $x_{2}$ does not, then reproduce $x_{1}$.

3.2 If both $x_{1}$ and $x_{2}$ do or do not dominate every individual in set $C$, then reproduce the one with smaller niche count.

4.Repeat the process until $N$ individuals are reproduced.

Furthermore, a hybrid MOGA is constructed in this research by incorporating a G-bit local search algorithm at the end of the above MOGA in order to reach an

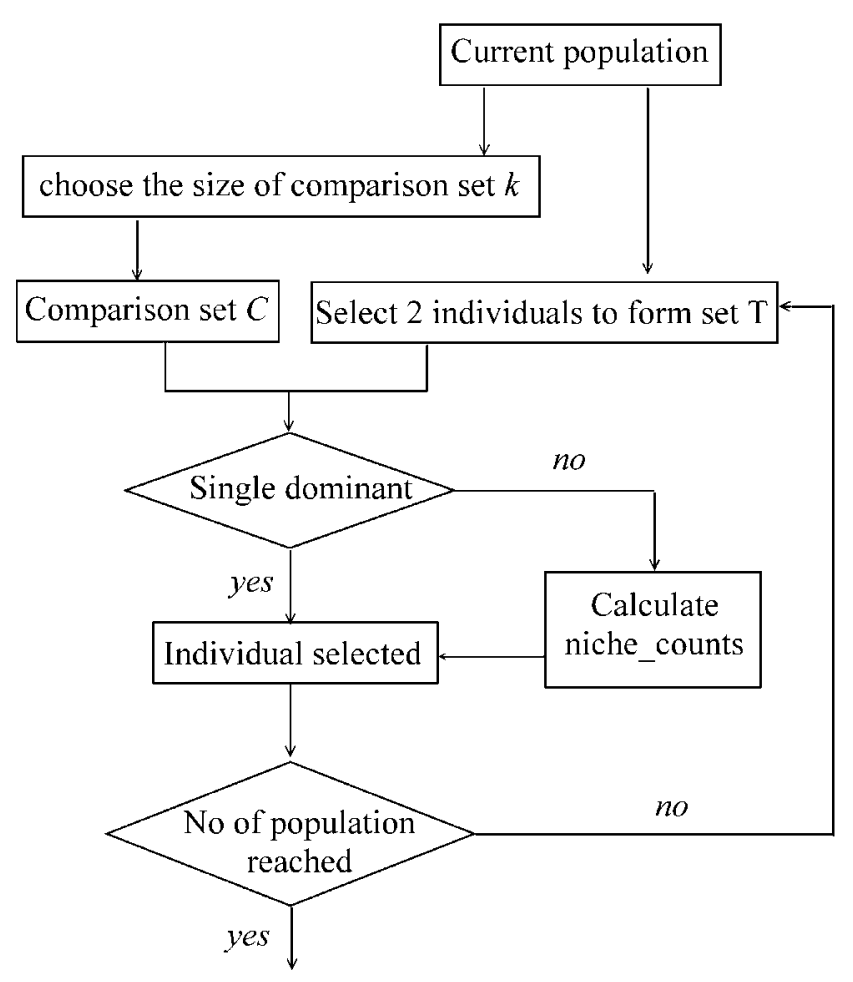

Fig. 8. Flow chart of tournament sharing selection. 
improved set of near optimal solutions. The local search will enhance the Pareto set found from the MOGA that usually does not reach the actual optimums due to the random search used. A flow chart being shown in Figure 9 details the complete hybrid MOGA.

In running the genetic algorithm for the ELID grinding process, crossover, mutation and selection were repeated with initial population of 30 of which each was coded by 64 bits string with 16 bits for every one of the four machining parameters. The crossover rate was chosen to be 1 and mutation rate to be 0.02 .

Once the ANFIS models of ELID grinding process were built and tested, the Hybrid MOGA program was then executed to determine for the best Pareto solution set using the flow chart as shown in Figure 9 to minimize the surface roughness and maximize the material removal rate. The resultant Pareto set consisting of 50 individuals is shown in Figure 10 and represent the set of optimal (non-dominant) solutions for this multiobjective optimization of ELID grinding process.

Finally the G-bit local search algorithm was run to enhance the Pareto set that ended with 39 better solutions from the 50 solutions in original Pareto set. A least distance method was then used to choose one solution from the Pareto set for the process designer. It defines a center point $(x, y)=$ (minimum of $R a$, maximum of

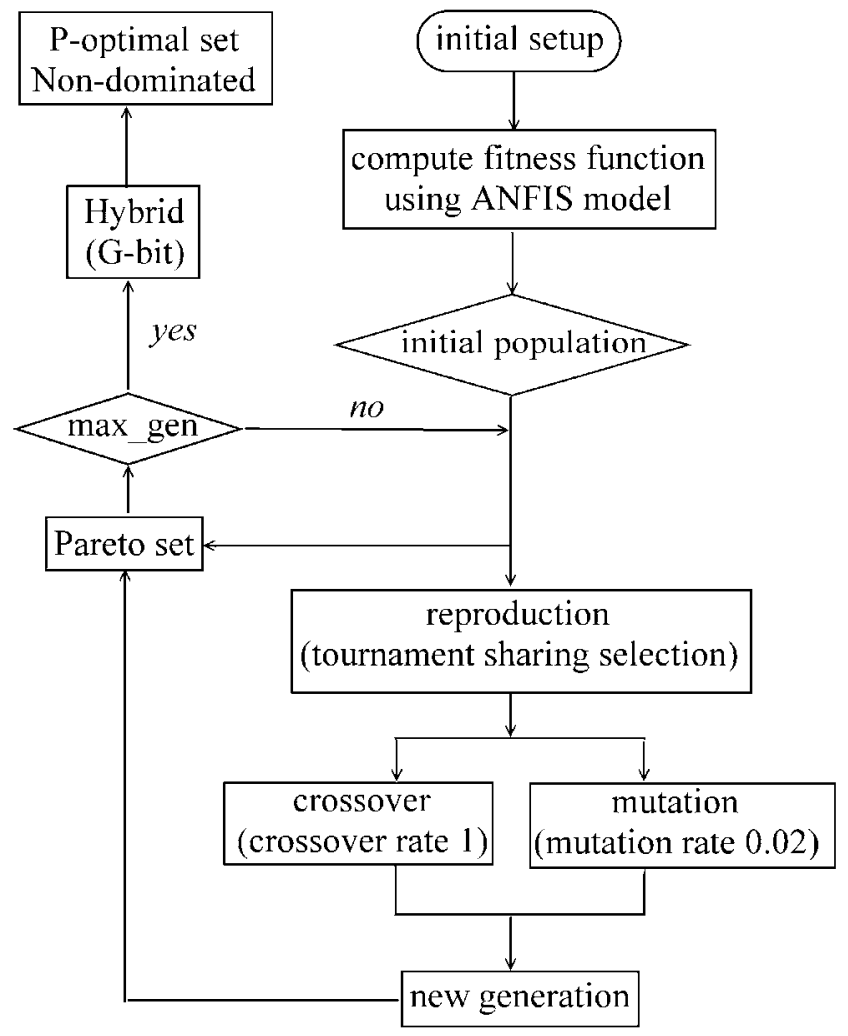

Fig. 9. Flow chart of the hybrid MOGA.
MRR) of the optimal Pareto set and chooses the closest point in the optimal Pareto set to this center point to be the single optimal solution. The single optimal solution found is [ [ 25.1 300.530$]$ for cutting speed, depth of cut, feed rate and current, and the results are surface roughness $=0.1745 \mu \mathrm{m}$ and $\mathrm{MRR}=1.8 \mathrm{~mm}^{3} / \mathrm{mm} \bullet \mathrm{sec}$. By comparing to results of the experiment using the optimal process parameters that has surface roughness of $0.169 \mu \mathrm{m}$, the error is within $4 \%$.

In running this Hybrid MOGA program, the selection process is based on the tournament sharing selection and the size of set $C$ is chosen to be two. Because the sharing function is used in selection, a niche count has to be calculated that requires a suitable parameter $\sigma_{\text {share }}$. In order to find the $\sigma_{\text {share }}$ for best results, a series of $\sigma_{\text {share }}$ were run to find a suitable one for this problem that shows $\sigma_{\text {share }}=0.1$ results in the best surface fitness.

\section{CONCLUSIONS}

An ELID precision grinding system was built for a conventional grinding machine center aided by a CNC control system and a low cost power supply. This system was used to machine ceramic materials (eg. $\mathrm{Al}_{2} \mathrm{O}_{3}$ ) to establish the best conditions for low surface roughness and high material removal rate. Grinding experiments with and without using ELID were performed to evaluate the improvement of surface quality and cutting energy. Results obtained show $13 \%$ average improvement in surface roughness, $50 \%$ reduction of tangential cutting force, and $21 \%$ reduction for normal cutting force when the ELID system was used. In Lim et al. [13] that used grinding wheel of \#4000 to process glass, the surface roughness can be improved up to 12 times.

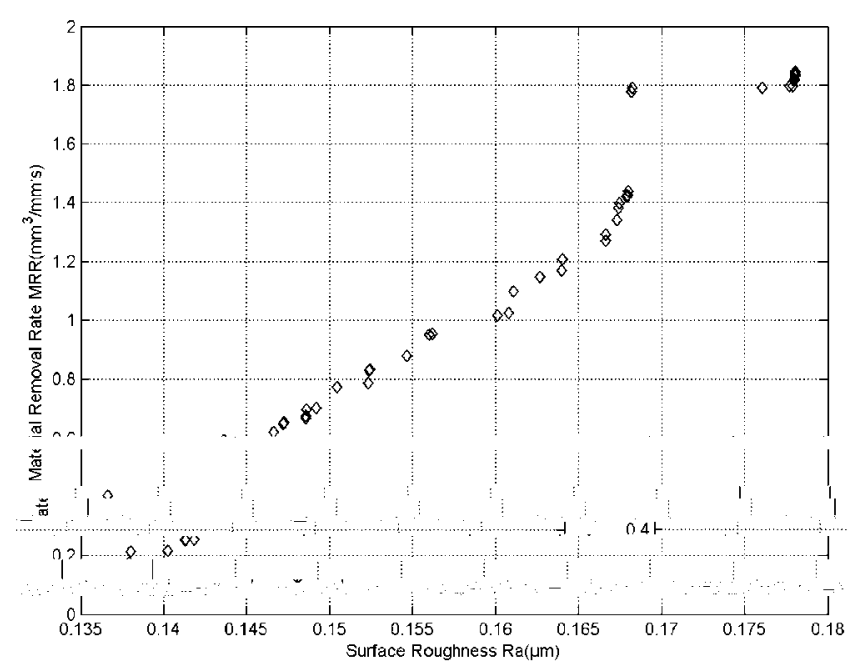

Fig. 10. Pareto set result of the MOGA. 
The Experimental results were also used to analyze statistically the influence of process parameters on the resultant surface quality and cutting forces. The analysis showed that surface roughness was affected mainly by depth of cut $(a)$ and cutting speed times depth of cut ( $r a)$, tangential cutting force affected mainly by constant $c$, cutting speed ( $r$ ) and square of cutting speed $\left(r^{2}\right)$, and normal cutting force affected mainly by feed rate $(f)$ and square of cutting speed $\left(r^{2}\right)$. More experimental data was then used to built Neuro-Fuzzy models of the machining process that in turn were used for process parametric optimization. A Hybrid Multi-Objective Genetic Algorithm (Hybrid MOGA) that combined a tournament sharing selection algorithm with Gbit local search method was constructed and used to find a set of non-dominant optimal solutions for the ELID grinding process for $\mathrm{Al}_{2} \mathrm{O}_{3}$.

\section{ACKNOWLEDGEMENTS}

The authors acknowledge the supports from the National Science Council, Taiwan, with grant of Precision Grinding project and the Ministry of Education with grant of Aerospace Quality Assurance project.

\section{REFERENCES}

1. Andrew, C., Howes, T.D., and Pearce, T.R.A. Creep Feed Grinding, Holt, Rinehart and Winston Ltd., East Sussex., UK, (1985).

2. Bandyopadhyay, B.P., Ohmori, H., and Takahashi, I., "Efficient and Stable Grinding of Ceramics by Electrolytic In-Process Dressing (ELID)," J. Mater. Proce. Technol., Vol. 66, pp. 18-24 (1997).

3. Bandyopadhyay, B.P. and Ohmori, H., "The effect of ELID grinding on the flexural strength of silicon nitride," Int. J. Machine Tools Manufact., Vol. 39, pp. 839-853 (1999).

4. Cohn, J.L., Multiobjective Programming and Planning, Academic, San Diego, CA (1978).

5. Fonseca, C. and Fleming, C., "Genetic Algorithms for Multiobjective Optimization: Formulation, Discussion and Generalization," Proceedings of 5th International Conference on Genetic Algorithms, pp. 416-423 (1993).

6. Gen, M. and Cheng, R., Genetic Algorithms and Engineering Design, John Wiley and Sons, Inc., New York (1997).

7. Goldberg, D.E., Genetic algorithms in Search, Optimization and Machine Learning, Addison-Wesley, USA, (1989).
8. Itoh, N. and Ohmori, H., "Grinding Characteristics of Hard and Brittle Materials by Fine Grain Lapping Wheels with ELID," J. Materi. Proc. Technol., Vol. 62, pp. 315320 (1996).

9. Jang, J.-S.R., “ANFIS: Adaptive-network-based fuzzy inference System," IEEE Trans. System, Man Cybernetics, Vol. 23, No. 3, pp. 665-684 (1993).

10. Kim, J.-D. and Lee, Y.-J., "Mirror Surface Grinding for Brittle Materials with In-Process Electrolytic Dressing," J. Mater. Engin. Perform., Vol. 3, No. 1, pp. 159-167 (1994).

11. Konig, W. and Wemhoner, J., "Optimizing Grinding of SiSiC," Ceramic Bull., Vol. 68, No. 3, pp. 545-548 (1989).

12. Li, K. and Liao, W., "Modeling of Ceramic Grinding Processes - Part I. Number of Cutting Points and Grinding Forces per Grit," J. Mater. Proc. Technol., Vol. 65, pp. 1-10 (1997).

13. Lim, H.S., Fathima, K., Kumar, A. S., and Rahman, M., "A Fundamental Study on the Mechanism of Electrolytic In-Process Dressing (ELID) Grinding," Int. J. Machine Tools Manufact., Vol. 42, pp. 935-943 (2002).

14. Malkin, S., Grinding Technology - Theory and Applications of Machining with Abrasive, Ellis Horwood Limited, Chichester, England, (1989).

15. Malkin, S. and Ritter, J.E., "Grinding Mechanisms and Strength Degradation for Ceramics," J. Engin. Indust., Vol. 111, pp. 167-173 (1989).

16. Man, K.F., Tang, K.S., and Kwong, S., "Genetic Algorithms Concepts and Applications," IEEE Trans. Indust. Electronics, Vol. 43, No. 5, pp. 519-533 (1996).

17. Nauck, K.D., Klawonn, F., and Kruse, R., Foundations of Neuro - Fuzzy System, John Wiley, New York, (1997).

18. Nian, C.Y., Yang, W.H., and Tarng, Y.S., "Optimization of Turning Operations with Multiple Performance Characteristics," J. Mater. Proce. Technol., Vol. 95, pp. 90-96 (1999).

19. Ohmori, H. and Nakagawa, T., "Mirror Surface Grinding of Silicon Wafers with Electrolytic In-Process Dressing," Annals CIRP, Vol. 39, No. 1, pp. 329-332 (1990).

20. Ohmori, H., Takahashi, H., and Bandyopadhyya, B.P., "Highly Efficient Grinding of Ceramic Parts by Electrolytic In-Process Dressing (ELID) Grinding," Materials Manufact. Proce., Vol. 11, No. 1, pp. 31-44 (1996).

21. Schaffer, J.D., "Multiple Objective Optimization with Vector Evaluated Genetic Algorithm," Proceedings of First International Conference on Genetic Algorithm and Their Applications, pp. 93-100 (1985). 